\title{
Maternal Selenium, Copper and Zinc Concentrations in Early Pregnancy, and the Association with Fertility
}

\author{
Jessica A. Grieger $1,2,+, * \mathbb{C}$, Luke E. Grzeskowiak $1,2,+(\mathbb{C}$, Rebecca L. Wilson $1,2,3 \oplus$, \\ Tina Bianco-Miotto ${ }^{1,4}{ }^{\mathbb{D}}$, Shalem Y. Leemaqz ${ }^{1,2}$, Tanja Jankovic-Karasoulos ${ }^{1,2}$, \\ Anthony V. Perkins ${ }^{5}$ (D), Robert J. Norman ${ }^{1,6}$, Gus A. Dekker ${ }^{1,7}$ and Claire T. Roberts ${ }^{1,2}$ \\ 1 Robinson Research Institute, University of Adelaide, 5005 North Adelaide, South Australia, Australia \\ 2 Adelaide Medical School, University of Adelaide, 5005 Adelaide, South Australia, Australia \\ 3 Current affiliation: Center for Fetal and Placental Research, Cincinnati Children's Hospital and Medical \\ Center, Cincinnati, OH 45229, USA \\ 4 Waite Research Institute, School of Agriculture, Food and Wine, University of Adelaide, 5064 Adelaide, \\ South Australia, Australia \\ 5 School of Medical Science, Griffith University, Gold Coast Campus, 4215 Southport, Queensland, Australia \\ 6 Fertility SA, 5000 Adelaide, South Australia, Australia \\ 7 Women and Children's Division, Lyell McEwin Hospital, University of Adelaide, 5112 Adelaide, South \\ Australia, Australia \\ * Correspondence: jessica.grieger@adelaide.edu.au \\ + These two authors contributed equally to this paper.
}

Received: 30 June 2019; Accepted: 14 July 2019; Published: 16 July 2019

check for updates

\begin{abstract}
Trace elements such as zinc, copper, and selenium are essential for reproductive health, but there is limited work examining how circulating trace elements may associate with fertility in humans. The aim of this study was to determine the association between maternal plasma concentrations of zinc, copper, and selenium, and time to pregnancy and subfertility. Australian women $(n=1060)$ who participated in the multi-centre prospective Screening for Pregnancy Endpoints study were included. Maternal plasma concentrations of copper, zinc and selenium were assessed at $15 \pm 1$ weeks' gestation. Estimates of retrospectively reported time to pregnancy were documented as number of months to conceive; subfertility was defined as taking more than 12 months to conceive. A range of maternal and paternal adjustments were included. Women who had lower zinc (time ratio, $1.20(0.99-1.44))$ or who had lower selenium concentrations $(1.19(1.01-1.40))$ had a longer time to pregnancy, equivalent to a median difference in time to pregnancy of around 0.6 months. Women with low selenium concentrations were also at a 1.46 (1.06-2.03) greater relative risk for subfertility compared to women with higher selenium concentrations. There were no associations between copper and time to pregnancy or subfertility. Lower selenium and zinc trace element concentrations, which likely reflect lower dietary intakes, associate with a longer time to pregnancy. Further research supporting our work is required, which may inform recommendations to increase maternal trace element intake in women planning a pregnancy.
\end{abstract}

Keywords: time to pregnancy; trace elements; subfertility; fertility; selenium; zinc; copper; pregnancy

\section{Introduction}

Impaired fertility, the failure to achieve pregnancy after 12 months or more of regular unprotected sexual intercourse, afflicts millions of couples worldwide, placing a significant emotional and economic burden on themselves, their families, and society [1]. There are consistent behavioural, clinical and biological factors associated with infertility including poor dietary intake, cigarette smoking, advanced maternal age, obesity, and polycystic ovary syndrome. Additionally, there is emerging, albeit 
inconsistent, evidence to suggest that high dose and occupational level exposures to toxic metals such as mercury, cadmium, and lead, associate with reduced fecundity and fertility in couples conceiving naturally [2,3] or requiring assisted reproduction [4-7]. Importantly, these elements are not essential to human health.

Comparatively, trace elements such as zinc, copper, and selenium are essential for health and are necessary for reproductive health $[8,9]$. There is considerable evidence in pregnancy highlighting their effects on oxidant/antioxidant balance, but also their other roles such as cell proliferation (zinc), protein synthesis (selenium, zinc), and haematopoiesis (copper) [9]. There are established roles for selenium, zinc, and copper in relation to male fertility [10,11], but there is far less known about trace element concentrations and female conception. In a sample of 80 pregnancy planners, no association was found between plasma zinc and the likelihood for a positive pregnancy test [12]. In contrast, in 45 women undergoing in vitro fertilisation (IVF), higher urinary copper $(\geq 35.7 \mu \mathrm{g} / \mathrm{L})$ was associated with higher total number of oocytes retrieved and better embryo quality, and higher urinary copper and zinc $(\geq 1808 \mu \mathrm{g} / \mathrm{L})$ was associated with total number of embryos generated [13]. Further, women who had unexplained infertility had lower selenium in their follicular fluid, the microenvironment which nourishes and surrounds the oocyte, compared to women with tubal infertility and male factor infertility [14]. In addition, recent studies have demonstrated both positive and negative associations between selenium, zinc and copper in the follicular fluid of women with and without endometriosis, which is a common cause of infertility $[15,16]$. Overall, these studies were limited by small sample sizes or were in women undergoing IVF or in women who had fertility disorders and so might not be representative of the general population, making the relationship between certain trace elements and fertility unclear. A major challenge in evaluating the effects of certain exposures on fertility lies in recruiting a sufficiently large sample of women prior to pregnancy and following them prospectively. Retrospective time to pregnancy studies which recruit women during pregnancy and ask them to recall exposures prior to conception and the time taken to conceive, have emerged as a valid and informative epidemiological approach to better understanding factors influencing female fertility $[17,18]$. One limitation of this approach lies in the required assumption that data collected following conception, whether clinical or biological, is reflective of pre-conception exposure status. However, we have previously utilised this to investigate the effects of various factors such as pre-conception dietary intake, asthma medication use, or maternal metabolic health status on time to pregnancy [19-21]. Further, having previously assembled a large cohort of women to investigate the effects of early pregnancy trace element status on pregnancy outcomes [22], and knowing that previous research has demonstrated a strong correlation between early pregnancy and pre-conception concentrations of trace elements such as selenium [23], we were in the unique position to investigate the relationship between these factors and reported time to pregnancy.

The aim of this study was to determine the association between maternal plasma concentrations of the trace elements, zinc, copper, and selenium, and time to pregnancy and subfertility. We hypothesise that lower concentrations of trace elements will associate with longer time to pregnancy and a higher rate of subfertility.

\section{Materials and Methods}

\subsection{Study Population}

The Screening for Pregnancy Endpoints study (SCOPE) is a multi-centre prospective cohort study which recruited nulliparous women with singleton pregnancies from Adelaide (Australia), Auckland (New Zealand), Cork (Ireland), Leeds, London and Manchester (UK) $(n=5628)$. Data for this study was from the Adelaide cohort $(n=1164)$. Ethics approval was gained from the University of Adelaide ethics committee and all women provided written consent (approval no: REC 1712/5/2008).

Nulliparous women carrying a singleton pregnancy were recruited at 14-16 weeks' gestation from the Lyell McEwin Hospital, Adelaide, Australia between November 2004 and September 2008. Research 
midwives collected information on demographics, smoking, family, medical and gynecological history, diet and supplement use, height, weight, systolic and diastolic blood pressure, and waist circumference. A non-fasting plasma sample was obtained for biochemical measurement of copper, zinc, selenium and C-reactive protein (CRP). Exclusion criteria for the SCOPE study were women considered to be at high risk of preeclampsia, small for gestational age or preterm birth, those who previously had a cervical knife cone biopsy, had three or more pregnancy terminations or miscarriages, if their pregnancy was complicated by a known major fetal anomaly or abnormal karyotype or if they received interventions that may modify pregnancy outcome (e.g., aspirin, cervical suture), if they were taking high dose supplements, or had diabetes (type 1 or type 2 ) or hypertension and related disorders/treatment.

For this analysis, we excluded women where data on time to pregnancy was missing $(n=5)$ or where blood samples were unavailable for trace element analysis $(n=99)$, leaving a final cohort of 1060 .

\subsection{Trace Element Samples}

Non-fasting plasma was obtained from heparinised, venous blood samples taken at $15 \pm 1$ weeks' gestation. In order to measure trace element concentrations, plasma samples were digested in concentrated nitric acid $\left(\sim 70 \% \mathrm{HNO}_{3}\right)$ under pressure and at temperature as per our previous publication [22]. Samples were run alongside two internal standards: iridium and rhodium (Choice Analytical) at a concentration of $200 \mathrm{ppb}$ and an 8-point calibration, including blank, was carried out between $0.01 \mu \mathrm{g} / \mathrm{L}$ and $100 \mu \mathrm{g} / \mathrm{L}$. Copper, selenium and zinc concentrations were determined using inductively-coupled plasma mass spectrometry (ICP-MS) (Agilent 7700 ICP-MS; carried out by accredited CSIRO Analytical Services, South Australia). Laboratory surfaces were thoroughly cleaned to avoid contamination and all procedures were performed under conditions that ensured no trace mineral contamination. Samples were run in triplicate through the mass spectrometer. Concentration categories for each trace element were made in accordance with published pregnancy and laboratory studies values for second trimester of pregnancy, with reference points being the middle concentration ranges: copper $(<25.97 \mu \mathrm{mol} / \mathrm{L}, \geq 25.97$ to $\leq 34.78 \mu \mathrm{mol} / \mathrm{L},>34.78 \mu \mathrm{mol} / \mathrm{L}) ;$ zinc $(<7.80 \mu \mathrm{mol} / \mathrm{L}, \geq 7.80$ to $\leq 12.24 \mu \mathrm{mol} / \mathrm{L},>12.24 \mu \mathrm{mol} / \mathrm{L})$; selenium $(<0.95 \mu \mathrm{mol} / \mathrm{L}, \geq 0.95$ to $1.84 \mu \mathrm{mol} / \mathrm{L},>1.84 \mu \mathrm{mol} / \mathrm{L})$ [24]. However for selenium, no woman had a value over $1.84 \mu \mathrm{mol} / \mathrm{L}$, thus the categories were amended to: $<0.95 \mu \mathrm{mol} / \mathrm{L}$ vs $\geq 0.95 \mu \mathrm{mol} / \mathrm{L}$ [as the reference value]). To convert from SI units $(\mu \mathrm{mol} / \mathrm{L})$ to conventional units, the following equations were used: zinc $(\mu \mathrm{mol} / \mathrm{L} \times 6.53 \mu \mathrm{g} / \mathrm{dL})$; selenium $(\mu \mathrm{mol} / \mathrm{L}$ $\times 78.74 \mu \mathrm{g} / \mathrm{L})$; copper $(\mu \mathrm{mol} / \mathrm{L} \times 6.37 \mu \mathrm{g} / \mathrm{dL})$. In supplementary analysis, we categorised trace element concentrations according to tertiles, based on study population values.

\subsection{Assessment of Outcome}

Estimates of reported time to pregnancy (TTP) were derived from the following question "duration of sex without contraception before conception with father of baby". Values in months were recorded in a continuous fashion and used to define TTP. In this study, subfertility was defined as having a TTP of more than 12 months or use of assisted reproductive technologies. Women who conceived in their first month had a reported TTP of 1 month, with prolonged TTP censored at 12 months of attempting to conceive.

\subsection{Assessment of Covariates}

Maternal ethnicity was self-reported and binary coded as Caucasian or other (90\% were Caucasian). The socioeconomic index was developed in New Zealand and is a measure of the individual's socioeconomic position derived from a specific occupation [25]. It provides a value of 10-90 with a higher score indicating higher socioeconomic position [26]. Retrospectively reported data at this same visit was also obtained: cigarette use and any intake of alcohol per week in the 3 months pre-pregnancy were each binary coded as yes or no. Dietary intakes relating to the one month preceding conception was obtained using single item questions of specific foods. The use of single item questions has been shown to be useful to assess gross level estimates and rank individuals on intakes, rather than precise 
levels of intake [27]. Number of servings of foods was reported to the midwife for fruit (fresh fruit and fruit juice), green leafy vegetables (vegetables high in folate such as spinach, cabbage, lettuce, broccoli), fish (with prompts of fish such as salmon, trout, sardines, shellfish and shrimp) and key discretionary foods reported to be consumed from take-away or fast food outlets (i.e., frequency of intake of burgers, fried chicken, pizza and hot chips were totalled as 'fast food'). Frequency of fruit was categorised as $\geq 3$ times/day vs. $<3$ times/day; green leafy vegetables as $\geq 1$ times/day vs. $<1$ time/day; fish as $\geq 1$ time/week vs. $<1$ time/week; fast food as never vs. more than never [20]. Frequency of sexual intercourse was described and reported as the frequency of sexual intercourse, per month, in the three months prior to conception, with the presumed biological father of the baby. Intake of multivitamin supplement in the first trimester (yes/no) was determined as either a multivitamin tablet containing $\geq 2$ vitamins or $\geq 2$ single vitamin tablets or a single vitamin with folate at the same time point (e.g., vitamin $\mathrm{C}$ tablet plus folate supplement). Adjustments were also made for whether the multivitamin included the particular trace element of interest (i.e., in analyses assessing zinc concentrations, we adjusted for whether zinc (yes/no) was contained in the multivitamin). Paternal data included age, height, and weight, and was self-reported from the biological father.

\subsection{Statistical Analyses}

Frequencies and descriptive statistics of all women were expressed as $n(\%)$ or as means (standard deviation, SD). Median (inter-quartile range, IQR) was reported when continuous variables were not normally distributed. The impact of each trace element (in categories) on TTP was investigated using accelerated failure time models, as previously published $[19,20]$ with log normal distribution to estimate time ratios (TR) and 95\% CIs. Adjusted marginal estimates for median TTP according to trace element concentrations were calculated using the Stata 'margins' command, together with corresponding $95 \%$ CIs. Alternative distributions were investigated but the log normal distribution was selected based on providing the lowest $-2 \log$ likelihood and Akaike information criterion value. These TRs can be interpreted as the ratios of the median values of the duration (in months) to achieve pregnancy between the compared groups. A TR above 1 implies that a given exposure is associated with longer TTP, whereas a TR below 1 indicates a shorter TTP.

We used causal diagrams (directed acyclic graphs) to guide selection of potential confounders for which to control, based on a priori selection of variables associated with trace element concentrations and fertility. Three separate adjusted models were used. Model 1: maternal age, maternal body mass index (BMI), ethnicity, socioeconomic status, plasma CRP, pre-pregnancy alcohol consumption, pre-pregnancy smoking status, frequency of sexual intercourse prior to conception, multivitamin use in first trimester, and trace element of interest in multivitamin; Model 2: Model 1 plus pre-pregnancy intake of fast food, green leafy vegetables, fruit, and fish; Model 3: Model 2 plus paternal age and paternal BMI. This was a complete case analysis.

Statistical significance was defined as a two-sided $p$-value of $<0.05$. All statistical analyses were undertaken using Stata IC 14 (Stata, College Station, TX, USA).

\section{Results}

\subsection{Participant Characteristics}

Participant characteristics are reported in Table 1. In total, 1060 women were included of whom $894(84.3 \%)$ took $<12$ months to conceive, and $166(15.7 \%)$ took 12 months or more. Women who took longer to conceive tended to have a lower frequency of sexual intercourse, a lower percentage of consumed alcohol prior to conceiving, a lower percentage of consumed fruit, $\geq 3$ times per day, a higher percentage of consumed fish, $\geq 1$ time per week, and a higher percentage of the women consumed a multivitamin in the first trimester. 
Table 1. Characteristics of the study population $(n=1060)$.

\begin{tabular}{|c|c|c|}
\hline Maternal Characteristics & Fertile & Subfertile \\
\hline & $<12$ months & $\geq 12$ months \\
\hline & $894(84.3 \%)$ & $166(15.7 \%)$ \\
\hline Age (years), mean (SD) & $23.4(5.0)$ & $25.4(5.3)$ \\
\hline Maternal age, $\geq 35$ years, $\mathrm{n}(\%)$ & $20(2.2 \%)$ & $9(5.4 \%)$ \\
\hline Body mass index $(\mathrm{kg} / \mathrm{m} 2)$, mean (SD) & $26.7(6.3)$ & $28.6(7.3)$ \\
\hline Socioeconomic index, mean (SD) & $27.5(10.2)$ & $29.3(11.0)$ \\
\hline \multicolumn{3}{|l|}{ Ethnicity, n (\%) } \\
\hline Caucasian & $822(91.6)$ & $149(89.8)$ \\
\hline Other & $72(8.1)$ & $17(10.2)$ \\
\hline \multicolumn{3}{|l|}{ Trace element concentration } \\
\hline Copper $(\mu \mathrm{mol} / \mathrm{L})$, mean $(\mathrm{SD})$ & $30.3(5.4)$ & $30.5(6.1)$ \\
\hline Zinc $(\mu \mathrm{mol} / \mathrm{L})$, mean $(\mathrm{SD})$ & $9.4(2.2)$ & $9.16(2.7)$ \\
\hline Selenium $(\mu \mathrm{mol} / \mathrm{L})$, mean $(\mathrm{SD})$ & $73(12)$ & $71(11)$ \\
\hline Frequency of sexual intercourse prior to pregnancy ${ }^{a}$ & $18.1(16.7)$ & $15.4(16.1)$ \\
\hline Pre-pregnancy alcohol intake, yes (n \%) & $485(54.3)$ & $69(41.6)$ \\
\hline Pre-pregnancy smoking, yes (n \%) & $363(40.6)$ & $63(38.0)$ \\
\hline \multicolumn{3}{|l|}{ Pre-pregnancy food group intake (n \%) } \\
\hline Fast food, never & $58(8.3)$ & $10(6.9)$ \\
\hline Fruit, $\geq 3 /$ day & $63(7.1)$ & $6(3.6)$ \\
\hline Green leafy vegetables, $\geq 1$ /day & $227(25.4)$ & $45(27.1)$ \\
\hline Fish, $\geq 1 /$ week & $327(36.6)$ & $74(44.6)$ \\
\hline Multivitamin use in first trimester, yes (n \%) & $531(59.5)$ & $117(70.5)$ \\
\hline Multivitamin containing copper (n \%) & $234(26.2 \%)$ & $73(44.0 \%)$ \\
\hline Multivitamin containing selenium ( $\mathrm{n} \%)$ & $16(1.8 \%)$ & $3(1.8 \%)$ \\
\hline Multivitamin containing zinc (n \%) & $458(51.2 \%)$ & $104(62.7 \%)$ \\
\hline \multicolumn{3}{|l|}{ Paternal characteristics $(n=930)$} \\
\hline Age (years), mean (SD) & $26.7(6.5)$ & $28.7(6.1)$ \\
\hline Body mass index $\left(\mathrm{kg} / \mathrm{m}^{2}\right)$, mean (SD) & $26.9(5.1)$ & $28.1(5.5)$ \\
\hline Missing, $n=99$ & & \\
\hline
\end{tabular}

a Frequency of sexual intercourse, per month, in the three months prior to conception, with the biological father of the baby. SD, standard deviation

\subsection{Relationship between Trace Elements and Time to Pregnancy}

The relationship between each trace element concentration at $15 \pm 1$ weeks' gestation and TTP is presented in Table 2. Compared to the reference value, women who had lower selenium concentrations $(<0.95 \mu \mathrm{mol} / \mathrm{L}$ vs. $\geq 0.95 \mu \mathrm{mol} / \mathrm{L}$ ) had a longer TTP (adjusted TR, $1.19(1.01-1.40)$ ), corresponding to a median 3.2 vs. 2.6 months to conceive (Figure 1). Lower $(<7.80 \mu \mathrm{mol} / \mathrm{L})$ but not higher $(>12.24 \mu \mathrm{mol} / \mathrm{L})$ zinc concentrations were also associated with a longer time to pregnancy (adjusted TR, $1.20(0.99-1.44)$ ). Marginal estimates for median TTP in women with lower vs. normal zinc concentrations was 3.3 months vs. 2.7 months, respectively (Figure 1). There were no associations between copper concentrations and TTP. Excluding women requiring assisted reproductive technology (ART), Table S1 shows lower zinc concentrations $(<7.80 \mu \mathrm{mol} / \mathrm{L}$ vs. $\geq 7.80$ to $\leq 12.24 \mu \mathrm{mol} / \mathrm{L}$ ) were associated with longer TTP (adjusted $\mathrm{TR}, 1.21$ (1.01-1.44)). In all women, Table S2 shows similar time ratios when using study population zinc tertiles rather than laboratory reference ranges. For selenium, higher levels $(>0.97 \mu \mathrm{mol} / \mathrm{L}$ vs. $\geq 0.86$ to $\leq 0.97 \mu \mathrm{mol} / \mathrm{L}$ ) were associated with a shorter TTP (TR $0.80(0.65-0.99)$ ). 
Table 2. Association between plasma trace element concentration measured at $15 \pm 1$ weeks' gestation and time to pregnancy.

\begin{tabular}{cccccccc}
\hline $\begin{array}{c}\text { Trace } \\
\text { Element }\end{array}$ & $\begin{array}{c}\text { Concentration } \\
(\mu \mathrm{mol} / \mathbf{L})^{\mathbf{a}}\end{array}$ & $\mathbf{N}$ & $\%$ & $\begin{array}{c}\text { Unadjusted } \\
\text { Time Ratio }\end{array}$ & \multicolumn{2}{c}{ Adjusted Time Ratio (95\% CI) } \\
\hline Selenium & $<0.95$ & 634 & $59.8 \%$ & $1.10(0.96-1.26)$ & $1.14(0.99-1.30)$ & $1.17(1.00-1.37)$ & $1.19(1.01-1.40)$ \\
& $\geq 0.95$ & 426 & $40.2 \%$ & 1 & 1 & 1 & 1 \\
\hline Zinc & $<7.80$ & 237 & $22.4 \%$ & $1.24(1.05-1.46)$ & $1.19(1.01-1.41)$ & $1.17(0.98-1.40)$ & $1.20(0.99-1.44)$ \\
& $\geq 7.80$ to $\leq 12.24$ & 734 & $69.3 \%$ & 1 & 1 & 1 & 1 \\
& $>12.24$ & 88 & $8.3 \%$ & $1.14(0.89-1.46)$ & $1.17(0.92-1.49)$ & $1.08(0.80-1.47)$ & $1.05(0.77-1.44)$ \\
\hline Copper & $<25.97$ & 202 & & $1.03(0.87-1.22)$ & $1.05(0.89-1.24)$ & $1.04(0.86-1.25)$ & $1.04(0.86-1.26)$ \\
& $\geq 25.97$ to $\leq 34.78$ & 506 & & 1 & 1 & 1 & 1 \\
& $>34.78$ & 186 & & $1.03(0.87-1.23)$ & $0.98(0.82-1.17)$ & $0.94(0.76-1.16)$ & $0.97(0.78-1.21)$ \\
\hline
\end{tabular}

${ }^{a}$ Reference ranges from Abbassi-Ghanavati M. et al. [24]. ${ }^{\mathrm{b}}$ Adjusted for maternal age, maternal body mass index, ethnicity, socioeconomic status, plasma C-reactive protein, pre-pregnancy alcohol consumption, pre-pregnancy smoking status, frequency of sexual intercourse prior to conception, multivitamin use in first trimester, and trace element of interest in multivitamin. ${ }^{c}$ Adjusted for $b$ plus intake of fast food, green leafy vegetables, fruit, and fish in the one month prior to conception. ${ }^{\mathrm{d}}$ Adjusted for c plus paternal age and paternal body mass index.

\subsection{Relationship between Trace Element Concentrations and Subfertility}

Categories of trace element concentrations and risk for subfertility are presented in Table 3. Women with low selenium concentrations $(<0.95 \mu \mathrm{mol} / \mathrm{L}$ vs. $\geq 0.95 \mu \mathrm{mol} / \mathrm{L})$ were at a $1.46(1.06-2.03)$ greater relative risk for subfertility compared to women with higher selenium concentrations. Estimated probabilities of subfertility based on multivariate adjusted models corresponded to an absolute difference of $6.3 \%$ when comparing low to high selenium concentrations (Figure 2). There were no associations between copper and zinc concentrations and risk for subfertility. Excluding women requiring ART, Table S3 also shows that women with lower selenium concentrations were at a 1.60 (1.06-2.41) greater relative risk for subfertility compared to women with higher selenium concentrations. When using study population tertiles rather than laboratory reference ranges, there were no associations between any of the trace elements and subfertility (Table S4).

Table 3. Risk for subfertility ( $>12$ months to conceive) according to plasma trace element concentration measured at $15 \pm 1$ weeks' gestation.

\begin{tabular}{cccccccc}
\hline $\begin{array}{c}\text { Trace } \\
\text { Element }\end{array}$ & $\begin{array}{c}\text { Concentration } \\
(\mu \mathrm{mol} / \mathrm{L})^{\mathbf{a}}\end{array}$ & $\mathbf{N}$ & $\mathbf{n ~ ( \% )}$ & Unadjusted RR & Model 1 $^{\mathbf{b}}$ & Model 2 $^{\mathbf{c}}$ & Model 3 $^{\mathbf{d}}$ \\
\hline Selenium & $<0.95$ & 634 & $113(17.8)$ & $1.43(1.06-1.94)$ & $1.52(1.13-2.05)$ & $1.44(1.04-1.98)$ & $1.46(1.06-2.03)$ \\
& $\geq 0.95$ & 426 & $53(12.4)$ & 1 & 1 & 1 & 1 \\
\hline Zinc & $<7.80$ & 237 & $44(18.6)$ & $1.25(0.91-1.72)$ & $1.13(0.82-1.56)$ & $1.04(0.74-1.45)$ & $1.07(0.76-1.50)$ \\
& $\geq 7.80$ to $\leq 12.24$ & 734 & $109(14.9)$ & 1 & 1 & 1 & 1 \\
& $>12.24$ & 88 & $13(14.8)$ & $0.99(0.58-1.69)$ & $1.07(0.63-1.81)$ & $0.88(0.46-1.68)$ & $0.0 .76(0.38-1.53)$ \\
\hline Copper & $<25.97$ & 202 & $38(15.8)$ & $1.02(0.72-1.44)$ & $1.10(0.77-1.58)$ & $0.97(0.67-1.40)$ & $1.01(0.69-1.47)$ \\
& $\geq 25.97$ to $\leq 34.78$ & 506 & $93(15.5)$ & 1 & 1 & 1 & 1 \\
& $>34.78$ & 186 & $35(15.8)$ & $1.02(0.71-1.46)$ & $0.88(0.61-1.25)$ & $0.79(0.53-1.18)$ & $0.83(0.55-1.25)$ \\
\hline
\end{tabular}

Results displayed as relative risk (RR) and 95\% CI. ${ }^{a}$ Reference ranges from Abbassi-Ghanavati M. et al. [24]. b Adjusted for maternal age, maternal BMI, ethnicity, socioeconomic status, plasma C-reactive protein, pre-pregnancy alcohol consumption, pre-pregnancy smoking status, frequency of sexual intercourse prior to conception, multivitamin use in first trimester, and trace element of interest in multivitamin. ${ }^{c}$ Adjusted for b plus intake of fast food, green leafy vegetables, fruit, and fish, in the one month prior to conception. ${ }^{\mathrm{d}}$ Adjusted for c plus paternal age and paternal body mass index. 


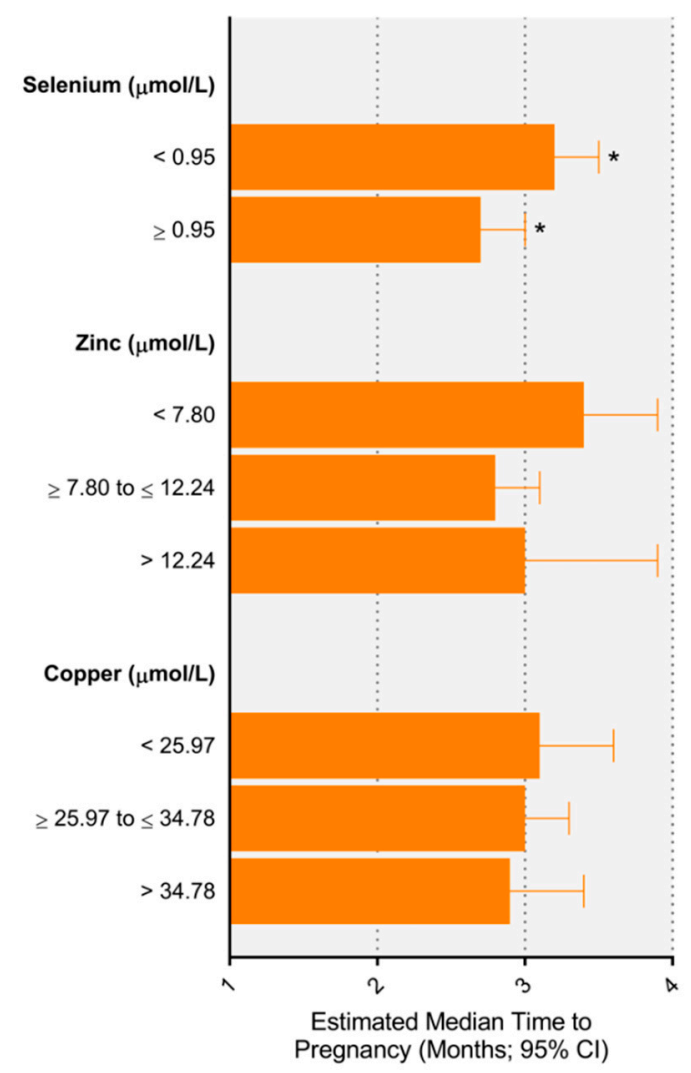

Figure 1. Estimated median time to pregnancy according to maternal trace element concentration. $* p<0.05$ between groups.

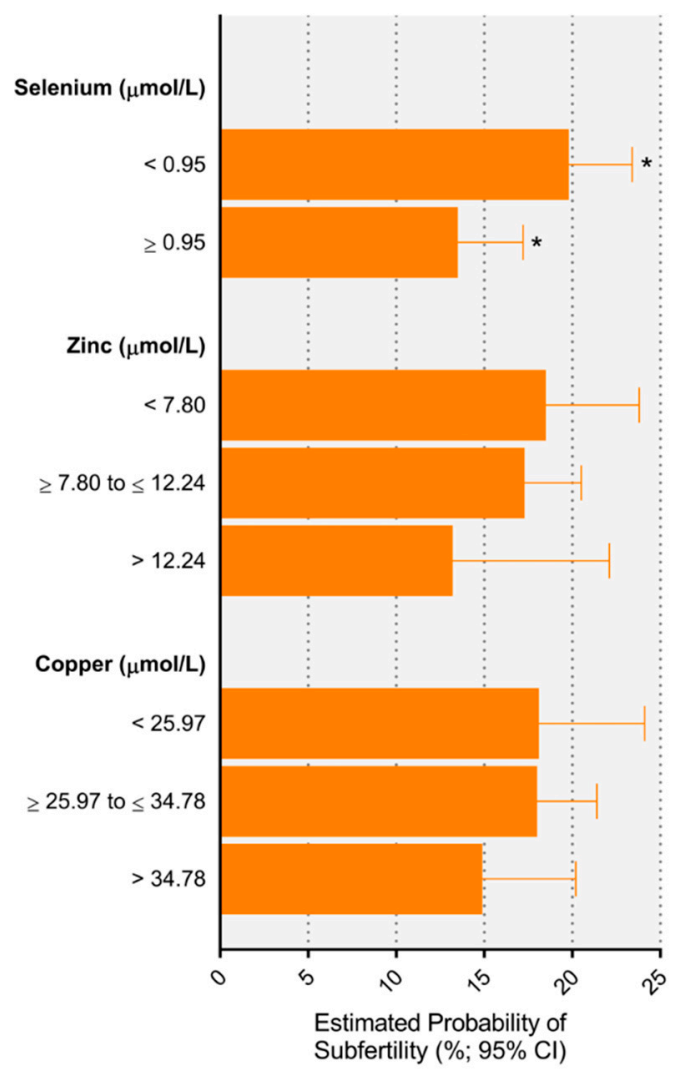

Figure 2. Estimated probability of subfertility according to maternal trace element concentration. $* p<0.05$ between groups. 


\section{Discussion}

This study provides novel insights into associations between trace element concentrations and TTP. We demonstrate that lower maternal plasma zinc and selenium concentrations were associated with an approximate one month longer TTP. Lower selenium concentrations were also associated with a $46 \%$ greater risk of subfertility, an absolute risk difference of $7 \%$ between subfertile and fertile women. Given the high prevalence of identified selenium and zinc deficiencies among this cohort, these finding could have important implications for improving fertility and warrant confirmation in subsequent studies, particularly where recruitment occurs prior to pregnancy.

Selenium is an essential trace mineral, mainly found in seafood, poultry, eggs, and organ meats [28,29]. The most commonly used measures of selenium status are plasma and serum selenium concentrations, which reflect recent dietary selenium intake [30]. Functional measures of selenium status include the glutathione peroxidases and selenoprotein $\mathrm{P}$ which play important roles in antioxidant defence, formation of thyroid hormones, and DNA synthesis, all of which impact fertility and reproduction $[8,10]$. While there have been studies demonstrating that low selenium status during pregnancy is associated with pregnancy complications [31], roles of selenium in periconceptual events such as oocyte development, fertilisation, and implantation, have not been addressed to a large extent. However, there are reports of its potential importance in follicle growth and maturation [10]. The importance of selenium in male fertility has been extensively studied in humans and animals, particularly in regard to the biosynthesis of testosterone but also potentially in sperm motility [10]. In our study, the demonstration that low maternal plasma selenium concentrations associate with a longer time to pregnancy and a $46 \%$ greater risk of subfertility, after adjusting for a range of maternal and paternal factors, lends additional support for its role in female reproduction. Furthermore, in our supplementary analysis, even after excluding women requiring ART, lower selenium concentrations were still associated with a longer TTP and a 60\% greater risk of infertility, in the final adjusted model. Additionally, we observed that selenium was not consumed in many multivitamin supplements across the fertile and subfertile groups. In restricting the analysis to only those who conceived naturally, we addressed any potential medical intervention bias, which occurs if the exposure of interest is also associated with the likelihood that couples would seek medical care for infertility. The mechanisms relating selenium to periconception health, particularly in women, require further investigation. Substantiating its effect on fertility may inform recommendations to increase maternal dietary selenium intake in women planning a pregnancy.

Women who had circulating zinc concentrations in the lowest reference range in early pregnancy took 0.6 months longer to conceive, compared with women in the middle tertile, after adjusting for maternal and paternal factors. Results were similar when excluding women requiring ART. Whilst the difference in TTP we observed only appears small, it is similar to the median difference in TTP with decreasing levels of fruit consumption and increasing levels of fast food consumption that we recently reported in the larger, international SCOPE cohort [19]. Diet is the main factor that determines zinc status [32]. In the United States and Australia, an additional 2-4 mg/day of zinc is recommended during pregnancy compared to non-pregnant women [28,33]. Fortunately many women across developed countries meet their country specific recommendations [34], suggesting adequate stores during pregnancy. Importantly, we show that at least half of all women consumed zinc in their multivitamin supplement. Zinc plays key roles in gene transcription, protein synthesis, and many other cellular processes including both antioxidant and pro-oxidant actions. Based on limited studies in women, the impact of maternal zinc concentrations on reproductive health prior to conception is inconclusive [35]. Studies in men have shown established roles for zinc in the synthesis of male sex hormones, sperm production and motility [10]. Furthermore, animal studies implicate zinc deficiency in impaired implantation [36], but also abnormal ovarian development, ovarian follicular growth, and oocyte maturation $[10,36]$. It is evident that zinc is required for key reproductive processes in animals and in men, and it is important in relation to adverse pregnancy outcomes in women. Whilst deficiencies in dietary zinc intake are not generally a problem in women in high income countries, 
a further understanding of whether, and how circulating zinc in women aids conception at the level of the oocyte and early embryo will help support our results on conception.

We found no association between maternal copper concentrations and TTP across any of the adjusted models. Copper is widely distributed in foods including organ meats, seafood, nuts and seeds, and it is biologically important for oxidative processes, energy metabolism, defence against free radicals, and for iron transport. Animal studies have shown copper deficiency in mice reduces fertilisation rates and oocyte recovery rate, but also heart and brain defects in the rat [36]. Using the same Adelaide SCOPE cohort, it was recently reported that women with lower plasma copper concentrations were protected against risk for any pregnancy complication when compared with women with high plasma copper [22], raising the possibility that copper may be more important for placentation rather than conception. In our cohort, only $26 \%$ and $44 \%$ of fertile and subfertile women, respectively, consumed copper in their multivitamin, but it is unclear whether this low percentage remarkably influenced the results. Further studies are required to determine the necessity of copper for early embryonic development and fertility in humans, and how oxidative damage from copper deficiency or toxicity may contribute to the occurrence of developmental defects in offspring.

Strengths of this study include the large sample size, detailed collection of maternal and paternal factors and information on the method of conception. The population was a community cohort of low risk nulliparous women, most of whom did not require any fertility treatment. In terms of study design, Jukic et al. highlight the strength of retrospective TTP studies in their ability to achieve a sample that is representative of the target population (i.e., women planning pregnancy), whereas prospective TTP studies that require the recruitment of highly motivated couples, introducing the potential for response and planning bias [37]. Limitations include the assessment of trace elements which were measured at 14-16 weeks' gestation, rather than pre-pregnancy, thus we do not know whether such measurements truly reflect those at the time women were trying to conceive. Notably, the use of non-fasting samples for assessment of zinc, selenium and copper have recently been shown to be similar to fasting samples [38]. Potential limitations of retrospective TTP studies have been well described by us $[19]$ and others $[17,18]$ and include the potential for planning bias, medical intervention bias, truncation bias and behaviour change bias. We did not have data on menstrual cycle length which is often utilised alongside defining TTP. However, TTP is considered easier to remember in retrospective studies than cycle length [39], and previous studies have demonstrated that correcting for menstrual patterns had no impact on effect estimates [40]. Finally, long term recall of TTP can only be roughly estimated compared to prospective studies, however, the use of self-reported time to pregnancy is consistent with that of previous studies, supporting the use of retrospective questionnaires to be accurate in the assessment of TTP in fertile and subfertile couples [18], and show good agreement with prospective recall of TTP [37].

\section{Conclusions}

Lower maternal plasma zinc and selenium concentrations were associated with longer TTP, and lower selenium concentrations were also associated with a greater risk for subfertility. Our work points towards pre-conception care, specifically with a focus on increasing trace micronutrient intake, which may support fertility. Further research supporting our work is required, particularly regarding pre-conception assessment of circulating trace elements but also pre-conception micronutrient intake both from diet and from supplemental intake. Further human studies are required to examine relationships between circulating trace elements and fertility, but also to determine how circulating trace elements correlate with the follicular fluid microenvironment. Mechanistic studies are necessary to determine how circulating trace elements influence oocyte and embryo quality and development.

Supplementary Materials: The following are available online at http://www.mdpi.com/2072-6643/11/7/1609/s1, Table S1: Association between plasma trace element concentration measured at $15 \pm 1$ weeks' gestation and time to pregnancy, excluding women requiring assisted reproduction technology. Table S2: Association between plasma trace element concentration, tertile measured at $15 \pm 1$ weeks' gestation and time to pregnancy. Table S3: Risk 
for subfertility ( $>12$ months to conceive) according to plasma trace element concentration measured at $15 \pm 1$ weeks' gestation, excluding women requiring assisted reproduction technology. Table S4: Risk for subfertility $(>12$ months to conceive) according to plasma trace element concentration tertile measured at $15 \pm 1$ weeks' gestation.

Author Contributions: Conceptualization, J.A.G, L.E.G and A.V.P.; methodology, J.A.G, L.E.G, R.J.N.; formal analysis, L.E.G, S.Y.L.; resources, R.L.W, T.B-M, T.J-K, G.A.D, C.T.R; data curation, G.A.D, C.T.R.; writing-original draft preparation, J.A.G.; writing-review and editing, all authors.

Funding: J.A.G. is supported by the EMPOWER NHMRC Centre for Research Excellence (GNT1099422) awarded to C.T.R., and G.A.D. C.T.R. is supported by a Lloyd Cox Professorial Research Fellowship, University of Adelaide. L.E.G acknowledges salary support from an Australian NHMRC Early Career Fellowship (ID1070421), Robinson Research Institute Career Development Fellowship and University of Adelaide Lloyd Cox Research Fellowship. Trace element analyses were funded by a Lloyd Cox Research Excellence Award, University of Adelaide, awarded to C.T.R.

Acknowledgments: We would like to thank John Gouzos and Claire Wright at the Analytical Services Unit (ASU) in CSIRO Land and Water, Waite Campus, University of Adelaide, for their time, assistance and expertise in measuring the plasma trace elements.

Conflicts of Interest: The authors declare no conflict of interest. The funders had no role in the design of the study, in the collection, analyses, or interpretation of data, in the writing of the manuscript, or in the decision to publish the results.

\section{References}

1. World Health Organisation. 2015. Available online: http://www.who.int/reproductivehealth/topics/infertility/ definitions/en/ (accessed on 6 May 2017).

2. Buck Louis, G.M.; Sundaram, R.; Schisterman, E.F.; Sweeney, A.M.; Lynch, C.D.; Gore-Langton, R.E.; Chen, Z.; Kim, S.; Caldwell, K.L.; Barr, D.B. Heavy metals and couple fecundity, the LIFE Study. Chemosphere 2012, 87, 1201-1207. [CrossRef] [PubMed]

3. Mendola, P.; Messer, L.C.; Rappazzo, K. Science linking environmental contaminant exposures with fertility and reproductive health impacts in the adult female. Fertil. Steril. 2008, 89, e81-e94. [CrossRef] [PubMed]

4. Bloom, M.S.; Kim, K.; Kruger, P.C.; Parsons, P.J.; Arnason, J.G.; Steuerwald, A.J.; Fujimoto, V.Y. Associations between toxic metals in follicular fluid and in vitro fertilization (IVF) outcomes. J. Assist. Reprod. Genet. 2012, 29, 1369-1379. [CrossRef] [PubMed]

5. Chang, S.H.; Cheng, B.H.; Lee, S.L.; Chuang, H.Y.; Yang, C.Y.; Sung, F.C.; Wu, T.N. Low blood lead concentration in association with infertility in women. Environ. Res. 2006, 101, 380-386. [CrossRef] [PubMed]

6. Al-Saleh, I.; Coskun, S.; Mashhour, A.; Shinwari, N.; El-Doush, I.; Billedo, G.; Jaroudi, K.; Al-Shahrani, A.; Al-Kabra, M.; El Din Mohamed, G. Exposure to heavy metals (lead, cadmium and mercury) and its effect on the outcome of in-vitro fertilization treatment. Int. J. Hyg. Environ. Health 2008, 211, 560-579. [CrossRef] [PubMed]

7. Younglai, E.V.; Holloway, A.C.; Foster, W.G. Environmental and occupational factors affecting fertility and IVF success. Hum. Reprod. Update 2005, 11, 43-57. [CrossRef]

8. Hofstee, P.; McKeating, D.R.; Perkins, A.V.; Cuffe, J.S. Placental adaptations to micronutrient dysregulation in the programming of chronic disease. Clin. Exp. Pharmacol. Physiol. 2018, 45, 871-884. [CrossRef]

9. Spencer, B.H.; Vanderlelie, J.J.; Perkins, A.V. Essentiality of Trace Element Micronutrition in Human Pregnancy: A Systematic Review. J. Pregnancy Child Health 2015, 2, 1-7. [CrossRef]

10. Ceko, M.J.; O’Leary, S.; Harris, H.H.; Hummitzsch, K.; Rodgers, R.J. Trace Elements in Ovaries: Measurement and Physiology. Biol. Reprod. 2016, 94, 86. [CrossRef]

11. Tvrda, E.; Peer, R.; Sikka, S.C.; Agarwal, A. Iron and copper in male reproduction: A double-edged sword. J. Assist. Reprod. Genet. 2015, 32, 3-16. [CrossRef]

12. Bloom, M.S.; Louis, G.M.; Sundaram, R.; Kostyniak, P.J.; Jain, J. Associations between blood metals and fecundity among women residing in New York State. Reprod. Toxicol. 2011, 31, 158-163. [CrossRef] [PubMed]

13. Ingle, M.E.; Bloom, M.S.; Parsons, P.J.; Steuerwald, A.J.; Kruger, P.; Fujimoto, V.Y. Associations between IVF outcomes and essential trace elements measured in follicular fluid and urine: A pilot study. J. Assist. Reprod. Genet. 2017, 34, 253-261. [CrossRef] [PubMed]

14. Paszkowski, T.; Traub, A.I.; Robinson, S.Y.; McMaster, D. Selenium dependent glutathione peroxidase activity in human follicular fluid. Clin. Chim. Acta 1995, 236, 173-180. [CrossRef] 
15. Singh, A.K.; Chattopadhyay, R.; Chakravarty, B.; Chaudhury, K. Markers of oxidative stress in follicular fluid of women with endometriosis and tubal infertility undergoing IVF. Reprod. Toxicol. 2013, 42, 116-124. [CrossRef] [PubMed]

16. Turgut, A.; Ozler, A.; Goruk, N.Y.; Tunc, S.Y.; Evliyaoglu, O.; Gul, T. Copper, ceruloplasmin and oxidative stress in patients with advanced-stage endometriosis. Eur. Rev. Med. Pharmacol. Sci. 2013, 17, 1472-1478. [PubMed]

17. Joffe, M.; Key, J.; Best, N.; Keiding, N.; Scheike, T.; Jensen, T.K. Studying time to pregnancy by use of a retrospective design. Am. J. Epidemiol. 2005, 162, 115-124. [CrossRef] [PubMed]

18. Joffe, M.; Villard, L.; Li, Z.; Plowman, R.; Vessey, M. Long-term recall of time-to-pregnancy. Fertil. Steril. 1993, 60, 99-104. [CrossRef]

19. Grieger, J.A.; Grzeskowiak, L.E.; Bianco-Miotto, T.; Jankovic-Karasoulos, T.; Moran, L.J.; Wilson, R.L.; Leemaqz, S.Y.; Poston, L.; McCowan, L.; Kenny, L.C.; et al. Pre-pregnancy fast food and fruit intake is associated with time to pregnancy. Hum. Reprod. 2018. [CrossRef]

20. Grieger, J.A.; Grzeskowiak, L.E.; Smithers, L.G.; Bianco-Miotto, T.; Leemaqz, S.Y.; Andraweera, P.; Poston, L.; McCowan, L.M.; Kenny, L.C.; Myers, J.; et al. Metabolic syndrome and time to pregnancy: A retrospective study of nulliparous women. BJOG Int. J. Obstet. Gynaecol. 2019. [CrossRef]

21. Grzeskowiak, L.E.; Smithers, L.G.; Grieger, J.A.; Bianco-Miotto, T.; Leemaqz, S.Y.; Clifton, V.L.; Poston, L.; McCowan, L.M.; Kenny, L.C.; Myers, J.; et al. Asthma treatment impacts time to pregnancy: Evidence from the international SCOPE study. Eur. Respir. J. 2018, 51, 1702035. [CrossRef]

22. Wilson, R.L.; Bianco-Miotto, T.; Leemaqz, S.Y.; Grzeskowiak, L.E.; Dekker, G.A.; Roberts, C.T. Early pregnancy maternal trace mineral status and the association with adverse pregnancy outcome in a cohort of Australian women. J. Trace Elem. Med. Biol. 2018, 46, 103-109. [CrossRef] [PubMed]

23. Rayman, M.P.; Bath, S.C.; Westaway, J.; Williams, P.; Mao, J.; Vanderlelie, J.J.; Perkins, A.V.; Redman, C.W. Selenium status in U.K. pregnant women and its relationship with hypertensive conditions of pregnancy. Br. J. Nutr. 2015, 113, 249-258. [CrossRef] [PubMed]

24. Abbassi-Ghanavati, M.; Greer, L.G.; Cunningham, F.G. Pregnancy and laboratory studies: A reference table for clinicians. Obstet. Gynecol. 2009, 114, 1326-1331. [CrossRef] [PubMed]

25. Davis, P.; McLeod, K.; Ransom, M.; Ongley, P. The New Zealand Socio-Economic Index of Occupational Status (NZSEI) (Research Report No. 2); Statistics New Zealand: Wellington, New Zealand, 1997.

26. Galbraith, C.; Jenkin, G.; Davis, P.; Coope, P. New Zealand Socioeconomic Index 1996: User's Guide; Statistics New Zealand: Wellington, New Zealand, 1996.

27. Yaroch, A.L.; Tooze, J.; Thompson, F.E.; Blanck, H.M.; Thompson, O.M.; Colon-Ramos, U.; Shaikh, A.R.; McNutt, S.; Nebeling, L.C. Evaluation of three short dietary instruments to assess fruit and vegetable intake: The National Cancer Institute's food attitudes and behaviors survey. J. Acad. Nutr. Diet. 2012, 112, 1570-1577. [CrossRef] [PubMed]

28. Australian Government. Department of Health and Aging. Nutrient Reference Values for Australia and New Zealand Including Recommended Dietary Intakes; National Health and Medical Research Council: Canberra, Australia, 2006.

29. Rayman, M.P. Food-chain selenium and human health: Emphasis on intake. Br. J. Nutr. 2008, 100, $254-268$. [CrossRef] [PubMed]

30. Ross, A.C.; Caballero, B.; Cousins, R.J.; Tucker, K.L.; Ziegler, T.R. Modern Nutrition in Health and Disease, 11th ed.; Lippincott Williams \& Wilkins: Philadelphia, PA, USA, 2012.

31. Mariath, A.B.; Bergamaschi, D.P.; Rondo, P.H.; Tanaka, A.C.; Hinnig Pde, F.; Abbade, J.F.; Diniz, S.G. The possible role of selenium status in adverse pregnancy outcomes. Br. J. Nutr. 2011, 105, 1418-1428. [CrossRef] [PubMed]

32. Hotz, C. Dietary indicators for assessing the adequacy of population zinc intakes. Food Nutr. Bull. 2007, 28, S430-S453. [CrossRef] [PubMed]

33. Trumbo, P.; Yates, A.A.; Schlicker, S.; Poos, M. Dietary reference intakes: Vitamin A, vitamin K, arsenic, boron, chromium, copper, iodine, iron, manganese, molybdenum, nickel, silicon, vanadium, and zinc. J. Am. Diet. Assoc. 2001, 101, 294-301. [CrossRef]

34. Blumfield, M.L.; Hure, A.J.; Macdonald-Wicks, L.; Smith, R.; Collins, C.E. A systematic review and meta-analysis of micronutrient intakes during pregnancy in developed countries. Nutr. Rev. 2013, 71, 118-132. [CrossRef] 
35. Ebisch, I.M.; Thomas, C.M.; Peters, W.H.; Braat, D.D.; Steegers-Theunissen, R.P. The importance of folate, zinc and antioxidants in the pathogenesis and prevention of subfertility. Hum. Reprod. Update 2007, 13, 163-174. [CrossRef]

36. Keen, C.L.; Hanna, L.A.; Lanoue, L.; Uriu-Adams, J.Y.; Rucker, R.B.; Clegg, M.S. Developmental consequences of trace mineral deficiencies in rodents: Acute and long-term effects. J. Nutr. 2003, 133, 1477S-1480S. [CrossRef] [PubMed]

37. Jukic, A.M.; McConnaughey, D.R.; Weinberg, C.R.; Wilcox, A.J.; Baird, D.D. Long-term Recall of Time to Pregnancy. Epidemiology 2016, 27, 705-711. [CrossRef] [PubMed]

38. McAlpine, J.M.; McKeating, D.R.; Vincze, L.; Vanderlelie, J.J.; Perkins, A.V. Micronutrition status of pregnant women in South-East Queensland and their association with outcomes. Nutri. Metab. Insights 2019, in press.

39. Olsen, J.; Bolumar, F.; Boldsen, J.; Bisanti, L. Does moderate alcohol intake reduce fecundability? A European multicenter study on infertility and subfecundity. European Study Group on Infertility and Subfecundity. Alcohol Clin. Exp. Res. 1997, 21, 206-212. [CrossRef] [PubMed]

40. Hassan, M.A.; Killick, S.R. Negative lifestyle is associated with a significant reduction in fecundity. Fertil. Steril. 2004, 81, 384-392. [CrossRef] [PubMed]

(C) 2019 by the authors. Licensee MDPI, Basel, Switzerland. This article is an open access article distributed under the terms and conditions of the Creative Commons Attribution (CC BY) license (http://creativecommons.org/licenses/by/4.0/). 